\title{
OPTIMIZATION DESIGN OF GROUND GRID MESH OF 132/33KV SUBSTATION USING ETAP
}

\author{
U. U. Uma ${ }^{1}{ }^{*}$ L. O. Uzoechi $^{2}$ and B. J. Robert ${ }^{3}$

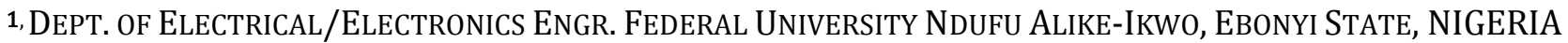

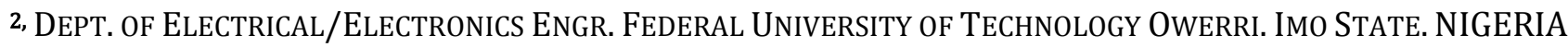

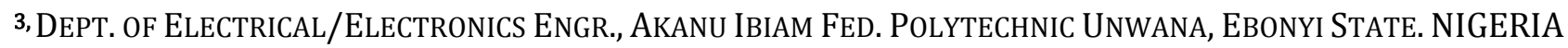 \\ E-mail addresses:1gbogbonna@yahoo.co.uk,2lazarus.uzoechi@futo.edu.ng,3bjrobert@akanuibiampoly.edu.ng
}

\begin{abstract}
This paper presents ground grid mesh design analysis and optimization of a 132/33kV substation. Ground grid mesh is made up of horizontal and vertical conductors connected with vertical rods buried under substation ground. The function of this structure is to effectively dissipate extremely high current generated in the system. The objective of this study is to determine the cost effective and safe ground grid mesh parameters by comparing mesh design analysis using IEEE and Finite Element Analysis (FEM) methods. The two methods are used differently to determine the ground grid mesh parameters, step \& touch voltages, horizontal and vertical number of conductors, vertical numbers of rods, and final substation Resistance. Etap 12.60 software is used for the analysis. Firstly, expected maximum short circuit current of OHIA $132 / 33 \mathrm{kV}$ substation is determined. Secondly, analysis is performed to determine input and output parameters of grid mesh structure using IEEE and FEM methods. An optimized result of IEEE method is determined. Analysis of both results is shown in different tables and recommendation is given regarding the best method for the grid mesh design.
\end{abstract}

Keywords: ETAP, ground grid mesh, design, optimization, finite element method, short-circuit current

\section{INTRODUCTION}

Grounding system for transmission substation is very important for stability of power system. It is described as system of electrical connection to the general mass of earth. This system of electrical connection consists of components of electrical system and metal works associated with the equipment, apparatus and appliances. This system provides protection to personnel, equipment and buildings and must have the ability of carrying short circuit current into earth under normal and fault conditions without exceeding operating and equipment limits or adversely affecting continuity of service [1]. The earth must be treated as semi-conductors while the grounding electrode itself as a pure conductor. These factors make the design of a grounding system complex, not derived from a simple calculation or the random driving of a few rod into the soil [2]. Due to the difference in soil characteristics at each substation, ground grid design must be carefully done to gain acceptable safety limit of all the parameters [3]. An accurate assessment of the site's soil condition is mandatory in other to determine the soil structure, type, depth and resistivity of each layer of the soil [1]. The primary requirement of earthing is to provide low earth resistance path for the dissipation of current in other to protect equipment personnel from excess current which may lead to equipment breakdown as well as loss of lives. If the resistance is high, more voltage drop will occur in mesh which will result in rise of mesh potentials [4]. A vertical rod is more effective electrode than a horizontal rod [3]. They discharge the grid current in the soil at sufficient depth thereby reducing soil resistance and Grid Potential Rise (GPR). With the presence of more ground rods, total length of conductors in the earth increases which causes decrease in step and mesh voltages. Ground rods are considered to be more effective way of reducing resistance of combine grounding system, actual mesh and step voltages whenever design modifications are necessary i.e. in actual practice [5]. There are three 
purposes of using grounding rods in a system grounding design. They are;

$>$ To reach to the lower earth layers which are less affected by environmental factors such as temperature and moisture content,

$>$ To protect the system operation as they are sited near surge arresters as close as possible to minimize the effectiveness of transient voltage.

$>$ To ground the fence of the grounding region separately [6].

The main issues related to ground grid design and determination of optimum method for substation mesh design is presented in this paper. The objective of this paper is to design ground grid mesh of a $132 / 33 \mathrm{kV}$ substation with expected maximum short circuit of $26 \mathrm{kA}$ such that the acceptable levels of step and touch potentials are held below their maximum permissible levels. The design analysis and optimization of grid mesh is carried out using two methods, Finite Element Analysis (FEM) and IEEE 802000. The two methods are compared to determine the most efficient and cost effective design for the proposed 132/33kV substation at Ohia. Latest Etap software 2014 version is used in the study.

\section{DETERMINATION OF SOIL RESISTIVITY.}

Soil resistivity is the key factor that determines what the resistance of the charging electrode will be and to what depth it must be driven to obtain low ground resistance. The resistivity of the soil varies widely throughout the world and changes seasonally. The lower the resistivity, the fewer the electrodes required to achieve the desired earth resistance value. Usually there are several soil layers with each having different resistivity which lead to non uniformity of the soil. Thus uniform soil is the soil that has one layer with constant value of resistivity [7]. Soil resistivity of a substation can be calculated using any of these four methods $[8,9]$

$>$ Wenner

$>$ Four point

$>$ Three point driven

$>$ Schlumberger.

Among the four methods, schlumberger is the most commonly used as testing procedure is easier and stratification type whether the soil is horizontally or vertically stratified can easily be judged [21].

\section{METHODS OF ANALYSIS}

\subsection{Finite Element Grounding Methods}

Most recent studies about grounding analysis are based on finite element methods FEM . It is used to determine grounding resistance of a design or a grounded region. They give more accurate results compared to conventional ground methods. FEM is one of the more reliable methods of finding ground grid mesh resistance. The resistance found is fairly close to the actual value compared to the one calculated using the conventional measurement methods[10].

Old FEM methods are composed of current flow analysis by using grid potential set. After the current is computed, ground resistance can be found by dividing voltage by current. However, the short coming of this method is selecting the size of the model such as earth distance to be considered is starting from the grounding grid. Since analysis of each potential in the soil for a selected point is considered from grounding grid to the point [5]. New FEM methods are developed by researchers such that main disadvantage of old FEM method is overcome. In new FEM, modeling starts from the following steps;

* In the first step, researchers assume that grounding resistance is such a parameter that does not depend on potential or current in the grid except frequency cases other than power frequencies $(50 \mathrm{~Hz}$ or $60 \mathrm{~Hz})$.

* Second assumption is that the region is an infinite flat surface [11]

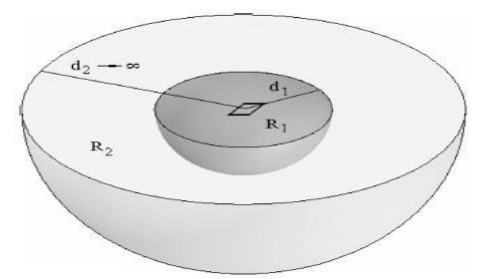

Fig 1 New finite element model of soil [15]

$R_{1}$ is the Resistance inside the semi-spherical surface, $R_{2}$ is the Resistance outside the semi-spherical surface, $d_{2}$ is the Distance from grid to the points where electrical potential goes to zero.

$d_{1}$ is the Distance from grid to the points where semispherical model of equipotent surface disturbs.

$$
d_{1}=\frac{D}{2}+30
$$

where $\mathrm{D}$ is the diagonal distance of grounding grid.

Resistance of grounding grid $[\mathrm{R}]$ is calculated from equation (2)

$$
R=R_{1}+R_{2}
$$

Resistance outside the semi spherical surface $R_{2}$ is calculated using equation (3)

$$
R_{2}=\frac{\rho}{2 \pi d_{1}}
$$


Determination of $R_{1}$ is not as simple as $R_{2}$. This is where finite element analysis exactly takes its place. Ingeneral $R_{1}$ can be calculated from dissipated power given in Eq. (4).

$$
R_{1}=\frac{(\text { Voltage })^{2}}{\text { Dissipated power }}
$$

$R_{1}$ can be detailed by replacing the terms as in Eq. (5).

$$
R_{1}=\frac{\left(V_{G}-V_{B}\right)^{2}}{\int_{v} \frac{E^{2}}{\rho} d v}
$$

$V_{G}$ is the potential in the grid, $V_{B}$ is the potential in the boundary. $d_{1}$ And $E$ is the Energy consume to do work From Eqs. (3) and (5), one can compute the grid resistance by Eq. (6).

$$
R_{g}=\frac{\left(V_{G}-V_{B}\right)^{2}}{\int_{v} \frac{E^{2}}{\rho} d v}+\frac{\rho}{2 \pi d_{1}}
$$

Finite Element Analysis can be also used to determine touch and step voltages. Once Rg is determined from FEM, step and touch voltages can be determined by the following steps.

Actual grid potential $\left(V_{A G}\right)$ is determined by Eq. (7) by finite element analysis.

$$
V_{A G}=R \cdot I_{G}
$$

where $I_{G}$ is actual fault current in A.

Actual boundary potential $\left(V_{A B}\right)$ is determined by Eq. (8) by finite element analysis.

$$
V_{A B}=R_{2} \cdot I_{G}
$$

\subsection{IEEE Methods of Grounding System Design.}

IEEE 80-2000 describes four different methods of determining ground resistance $R_{g}$ [12]. The methods are discussed hereunder.

3.2.1 Laurent-Niemann Method: The ground resistance is a function of the area covered by the substation and the soil resistivity in the substation region. Soil resistivity has a non-uniform nature and varies both vertically and horizontally in the earth region. $R_{g}$ can be calculated using eqn. (9)

$$
R_{g}=\frac{\rho}{4} \sqrt{\frac{\pi}{A}}+\frac{\rho}{L_{T}}
$$

where $\mathrm{A}$ is area covered by the substation in $m^{2}, L_{T}$ is total buried length of conductors, $\rho$ is the resistivity of soil.

$$
L_{T}=L_{t}+n_{R} \cdot h
$$

$L_{t}$ is the total length of conductors in grid in meters., $n_{R}$ is the number of grounding rods used in grid in meters., $h$ is the depth of the grid in meters. [13]
3.2.2 Sverak Method: This method is an integrated form of Laurent-Niemann Method. Ground resistance at the surface of the soil is modified in order to improve the accuracy of the ground resistance $R_{g}$ calculated. The work done in [14] observed significant effect of the grid depth on ground resistance and decided that this effect is large enough to be included into the equation Therefore, Eq. (9) is rearranged and the resultant Eq. (10) is obtained.

$$
R=\rho\left[\frac{1}{L_{t}}+\frac{1}{\sqrt{20 A}}\left(1+\frac{1}{1+h(\sqrt{20 / A})}\right)\right]
$$

Examining Laurent-Niemann and Sverak Equations, it can be easily understood that the resistance is directly proportional to resistivity and inversely proportional to total buried length of conductors and the following is observed. Increasing the area of grounding grid decreases the resistivity in the order of square root. Ground resistance decreases while using more conductors in grid design [14].

3.2. 3. Schwarz Method: This method is composed of three equations and one equation for merging the three.

$$
\begin{gathered}
R=\frac{R_{1} R_{2}-R_{m}{ }^{2}}{R_{1}+R_{2}-2 R_{m}} \\
R_{1}=\frac{\rho}{\pi L_{t}}\left[\operatorname{In}\left(\frac{2 L_{t}}{a^{\prime}}\right)+\frac{K_{1} L_{t}}{\sqrt{A}}-K_{2}\right]
\end{gathered}
$$

$2 \mathrm{a}$ is the diameter of conductor in m. $a^{\prime}$ is the $\sqrt{2 a h}$ for conductors buried at depth $\mathrm{h}$.

$K_{1}$ and $K_{2}$ are the coefficients found by the following equations according to the value of grid depth (h).

$$
\begin{aligned}
R_{2}=\frac{\rho}{2 \pi n_{R} L_{r}}[ & \ln \left(\frac{4 L_{r}}{b}\right)-1 \\
& \left.+\frac{2 K_{1} L_{r}}{\sqrt{A}}\left(\sqrt{n_{R}}-1\right)^{2}\right]
\end{aligned}
$$

where $L_{r}$ is the length of each rod in meters, $\mathrm{b}$ is the diameter of rod in meters,

$n_{R}$ number of rods placed in area A.

The third variable in Schwarz Equation is given in Eq. (14). $\mathrm{Rm}$ is the combined ground resistance of the grid and the rod bed. Reference [16] has the necessary derivations to obtain Schwarz equations

$$
R_{m}=\frac{\rho}{\pi L_{t}}\left[\ln \left(\frac{2 L_{t}}{L_{t}}\right)+\frac{K_{1} L_{t}}{\sqrt{A}}+1-K_{2}\right]
$$

3.2.4 Thapar-Gerez Method: Thapar-Gerez formula is given in Eq. (15) and this formula is the integrated version of Eq. (10). In detail, an extra multiplication part is added to include the effect of grounding region shapes on calculated resistance. 


$$
\begin{aligned}
R=\rho\left[\frac{1}{L_{T}}+\frac{1}{\sqrt{20 A}}\left(1+\frac{1}{1+h \sqrt{20 / A}}\right)\right] \\
\quad \times 1.52\left[2 \ln \left(L_{p} \sqrt{\frac{2}{A}}\right)-1\right] \frac{\sqrt{A}}{L_{p}} .
\end{aligned}
$$

Where $L_{P}$ is the peripheral length of grid.

\section{DESIGN PARAMETERS.}

The proposed $132 / 33 \mathrm{kV}$ Ohia substation is fed from $330 / 132 \mathrm{kV}$ Alaoji grid station as shown in figure 2 . Etap 12.6 software is used to design the network and also used to determine the expected maximum short circuit current. From fig 2, the maximum short circuit current at Ohia $132 / 33 \mathrm{kV}$ substation bus bar is 26.6kA. The grid mesh design is done manually to obtain the design parameters and the results verified using the software.

\section{DESIGN METHODOLOGY}

Step 1. Determine the following field data;

A. Area (A) of the substation using any of the following Square, Rectangular, Triangular, L- Shape, T-Shape methods.

B. soil resistivity of the site using any of the methods: Schlumberger, 3 point driven Rod, 4 point and wenner $[8,9]$.

C. Maximum expected short circuit current and maximum clearing time using Etap 12 software.
Step 2.Determine the conductor cross sectional area $A_{m m}{ }^{2}$ using equation 16.

$$
A_{m m}{ }^{2}=I \times \sqrt{\frac{\frac{t_{c} \times \alpha_{r} \times \rho_{r} \times 10^{4}}{T C A P}}{\ln \left[1+\frac{\left(T_{m}-T_{a}\right)}{\left(K_{0}+T_{a}\right)}\right]}}
$$

Step3. Step potential $\left(E_{\text {step }}\right)$ and touch potential $\left(E_{\text {touch }}\right)$ using eqn(17-20)

$$
\begin{gathered}
E_{\text {step }_{50}}=\left(1000+6 C_{S}\left(h_{S} K\right) \rho_{S}\right) \frac{0.116}{\sqrt{t_{s}}} \\
E_{\text {step }_{70}}=\left(1000+6 C_{S}\left(h_{S} K\right) P_{S}\right) \frac{0.157}{\sqrt{t_{s}}} \\
E_{\text {toch }_{50}}=\left(1000+1.5 C_{S}\left(h_{S} K\right) P_{S}\right) \frac{0.116}{\sqrt{t_{s}}} \\
E_{\text {toch }_{70}}=\left(1000+1.5 C_{S}\left(h_{S} K\right) P_{S}\right) \frac{0.157}{\sqrt{t_{s}}}
\end{gathered}
$$

Step 4. Determine the following; Depth of burial grid conductor, ground conductor spacing, crushed rock resistivity, Quantity of ground rod and calculate the number of conductors in $\mathrm{X}$ and $\mathrm{Y}$ axis and total length $\left(L_{t}\right)$ of grid conductor using the eqn. 21, 22 and 23.

$$
\begin{aligned}
X & =\frac{\text { width }}{D} \\
Y & =\frac{\text { length }}{D} \\
L_{t} & =Y \times \text { length }+X \times \text { width }
\end{aligned}
$$

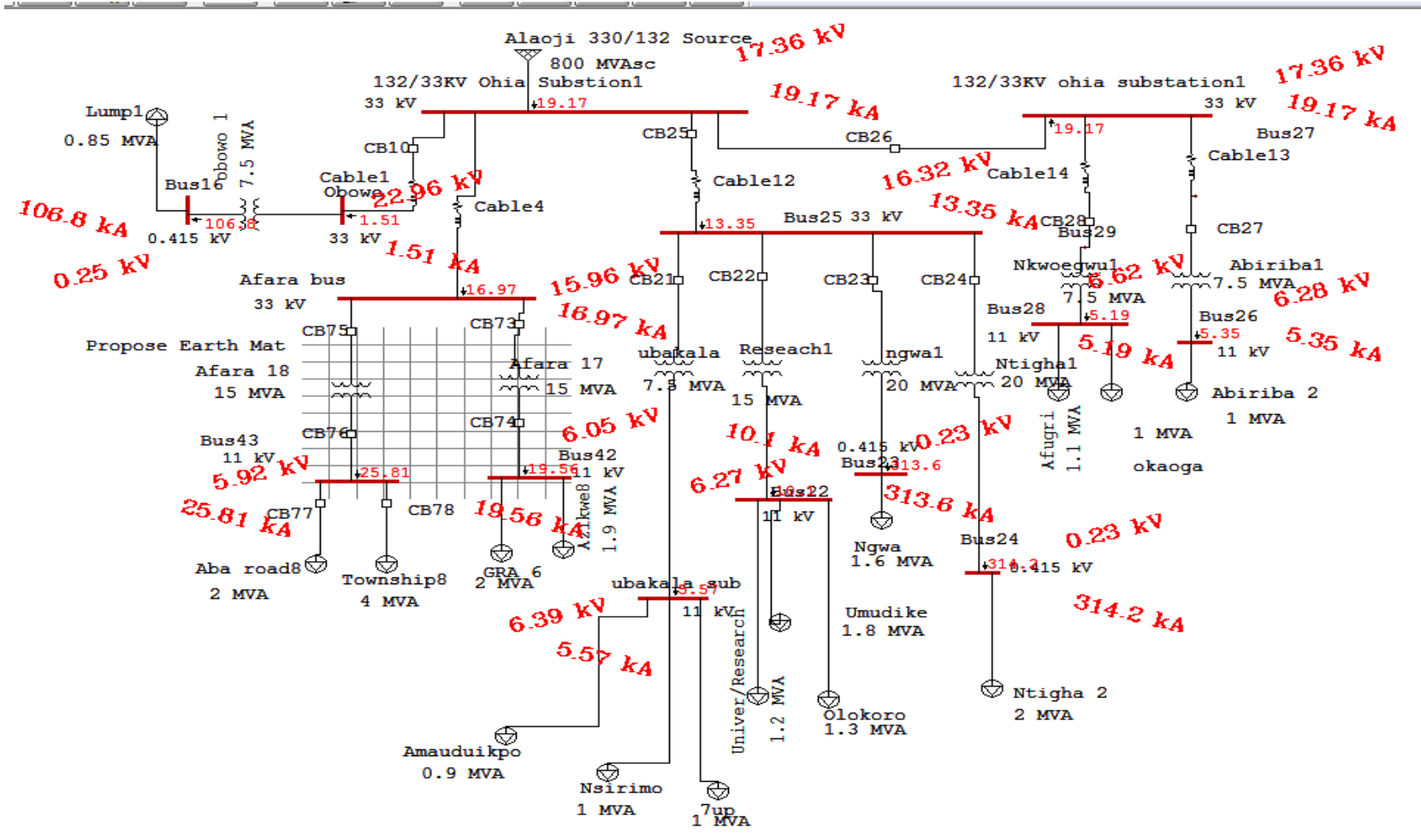

Fig 2: Alaoji substation network 


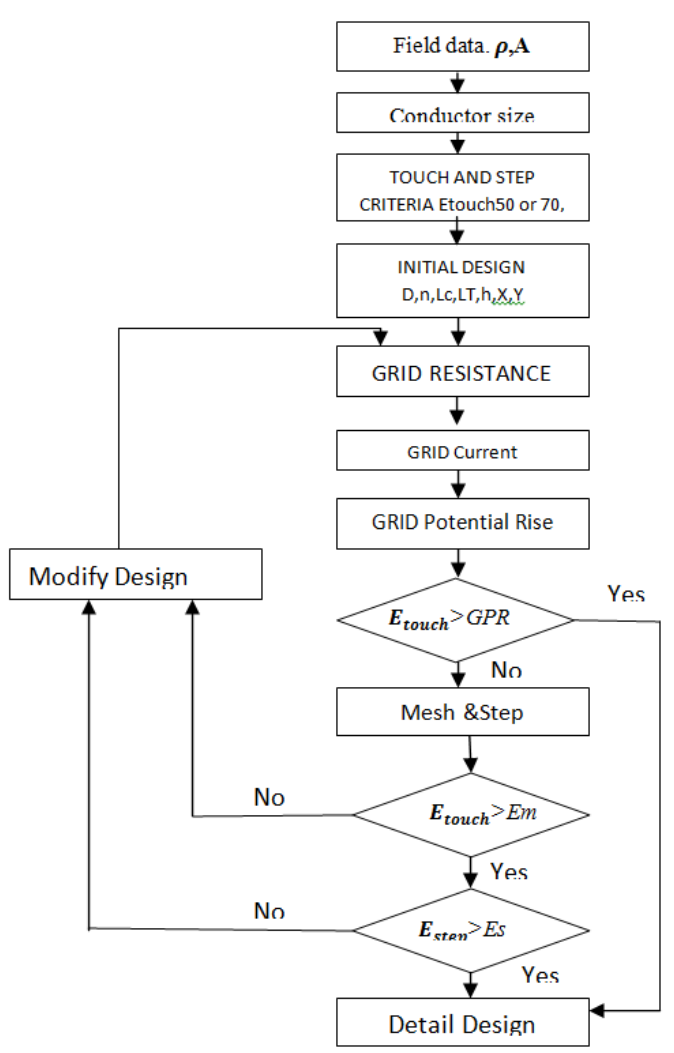

Figure 3: Design procedure block diagram

Step 5; Determine the ground grid resistance using any of equation (9), (10), (11) and (15). The most commonly used are (10) and (15) equations, as testing procedure is easy and stratification type, whether the soil is horizontally or vertically stratified can easily be judged by this method.

Step 6: Determine the grid current $\left(I_{g}\right)$ using eqn. 24 .

$$
I_{g}=3 S_{f} I_{0}
$$

Step 7: Determine the grid potential rise (GPR) using equation (25)

$$
G P R=I_{g} R_{g}
$$

Step 8:.If $E_{\text {touch }}$ is greater than GPRthen proceed to the detailed design otherwise go to step 9 .

$E_{\text {touch }}>G P R$

Step 9: Determine the mesh and Step voltages using equations 26 and 27

$$
\begin{gathered}
E_{\text {mesh }}=\frac{P K_{m} K_{i m} I_{g}}{L_{t}+1.15 L_{r} N_{r}} \\
E_{\text {step cal. }}=\frac{P K_{i} K_{i s} I_{g}}{L_{t}+1.15 L_{r} N_{r}}
\end{gathered}
$$

Step 10: If $E_{\text {touch }}$ is greater than mesh voltage then proceed to step 11 and if not move to step 12 .

Step 11: If $E_{\text {step }}$ is greater than calculated step voltage then proceed to detail design step 13 otherwise move to step 12

Step 12: Output detailed design

\section{GRID PARAMETERS FROM ETAP SOFTWARE}

Ground grid input data is generated from Etap 12 Software after the simulation as shown in Appendix A which shows all the input parameters and constants that are used for the design of ground mesh. These are the System data, Soil data, Material constant, Rod data, Grid configuration and Cost of Design.

\subsection{Case1. IEEE Method.}

The ground grid system module in Etap 12.6 has the provision of performing analysis using IEEE 80-2000 methods in three different ways and each generate different parameters. Table 1 show the input ground grid parameters upon which modeling are done. It shows grid mesh data for normal simulation, Optimized number of conductors and optimized number of rods and conductors as shown in Figures:

(4) through (7).

\begin{tabular}{|c|c|c|c|c|}
\hline \multicolumn{2}{|l|}{ Parameters } & $\begin{array}{c}\text { Grid } \\
\text { Configuration } \\
\text { for normal } \\
\text { Simulation }\end{array}$ & $\begin{array}{c}\text { Grid } \\
\text { Configuration } \\
\text { for Optimized } \\
\text { no of cond. }\end{array}$ & $\begin{array}{c}\text { Grid } \\
\text { Configuration } \\
\text { for optimized } \\
\text { no of rods \& } \\
\text { conductors }\end{array}$ \\
\hline \multicolumn{2}{|c|}{ Conductors Depth (ft) } & 6.00 & 6.00 & 6.00 \\
\hline \multirow{2}{*}{$\begin{array}{l}\text { Grid } \\
\text { Length (ft) }\end{array}$} & $\mathrm{Lx}$ & 300 & 300 & 300 \\
\hline & Ly & 300 & 300 & 300 \\
\hline \multirow{2}{*}{$\begin{array}{l}\text { No of } \\
\text { Conductors }\end{array}$} & $\mathrm{X}$ & 18 & 13 & 6 \\
\hline & $\mathrm{Y}$ & 18 & 13 & 6 \\
\hline \multirow{2}{*}{$\begin{array}{l}\text { Separation } \\
\text { Length }\end{array}$} & $\mathrm{X}$ & 17.6 & 25 & 60 \\
\hline & $\mathrm{Y}$ & 17.6 & 25 & 60 \\
\hline \multicolumn{2}{|l|}{$\begin{array}{l}\text { Total no of } \\
\text { Conductors }\end{array}$} & 36 & 26 & 12 \\
\hline \multicolumn{2}{|c|}{ No of rods } & 75 & 75 & 123 \\
\hline \multicolumn{2}{|c|}{ Length in ( ft ) } & 32.80 & 32.80 & 32.80 \\
\hline \multicolumn{2}{|c|}{ Ground Resistance } & 0.518 & 0.518 & 0.480 \\
\hline \multicolumn{2}{|c|}{ Total Cost of Design } & $\$ 2310.00$ & $\$ 1710.00$ & $\$ 966.00$ \\
\hline
\end{tabular}

Table1: Grid mesh data for normal simulation, optimized number of conductors and optimized number of rods and conductor

The results of analysis using IEEE 80-2000 methods for normal simulation. The result of analysis for optimized number of rods and conductors is shown in Figure 6.

\subsection{Case 2: FEM method.}

This shows the design of grid mesh of the proposed substation with maximum expected short circuit of 27kA using Finite Element Analysis method. Table 2 shows the input parameters for the design. 


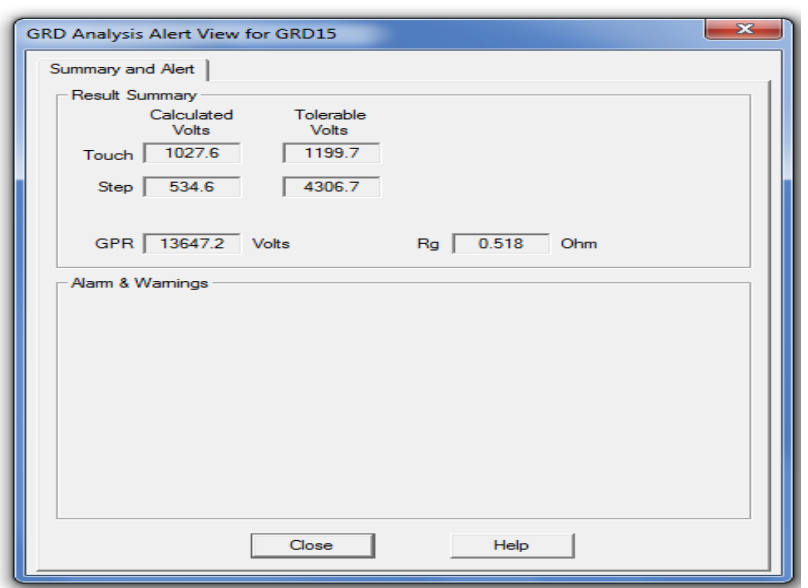

Fig 4; Grid Configuration for Normal Simulation.

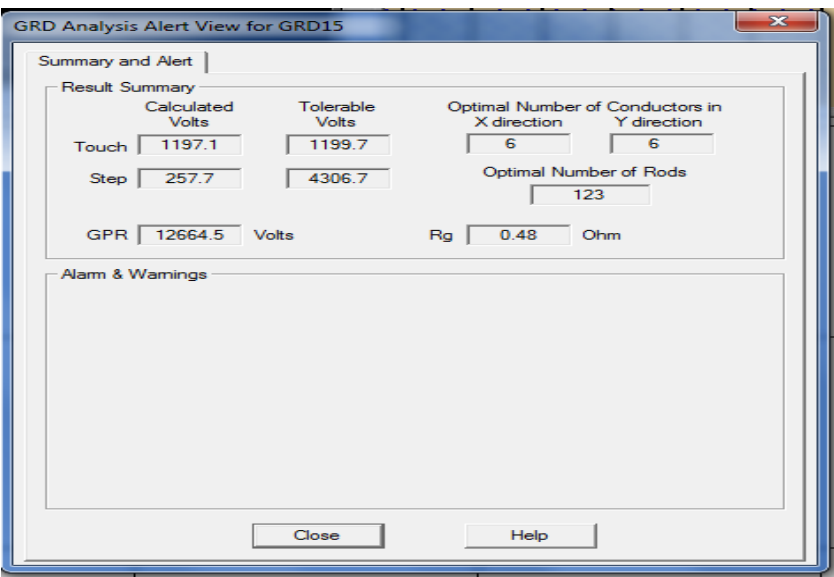

Fig. 6 Grid Configuration for optimized number of rods and conductors.

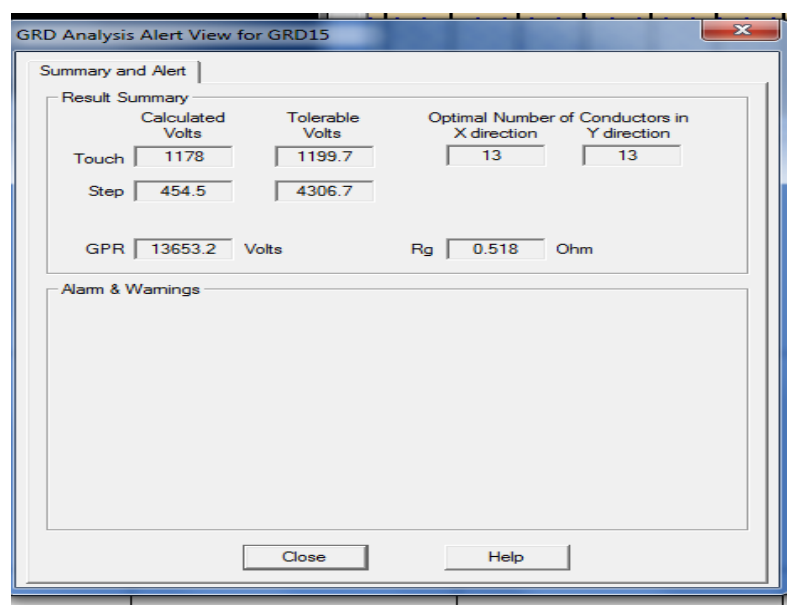

Fig.5 Grid Configuration for Optimized Number of conductors.

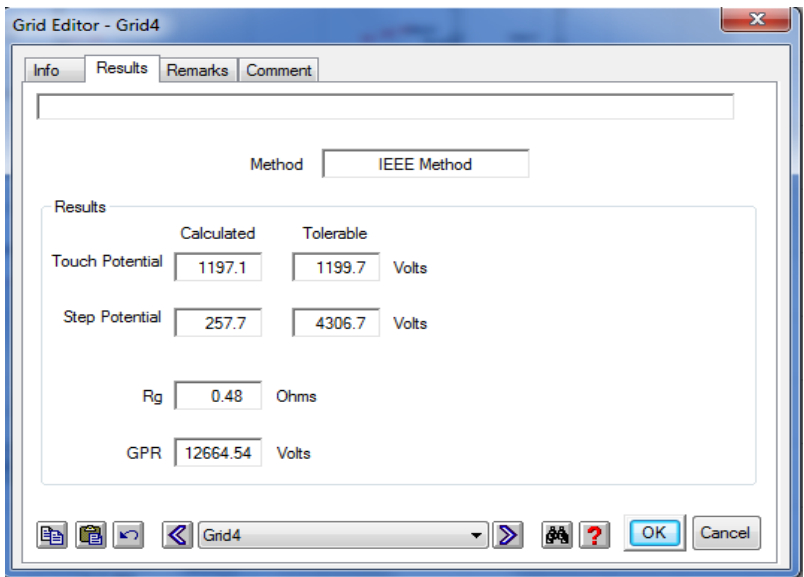

Fig7. Final result Using IEEE method

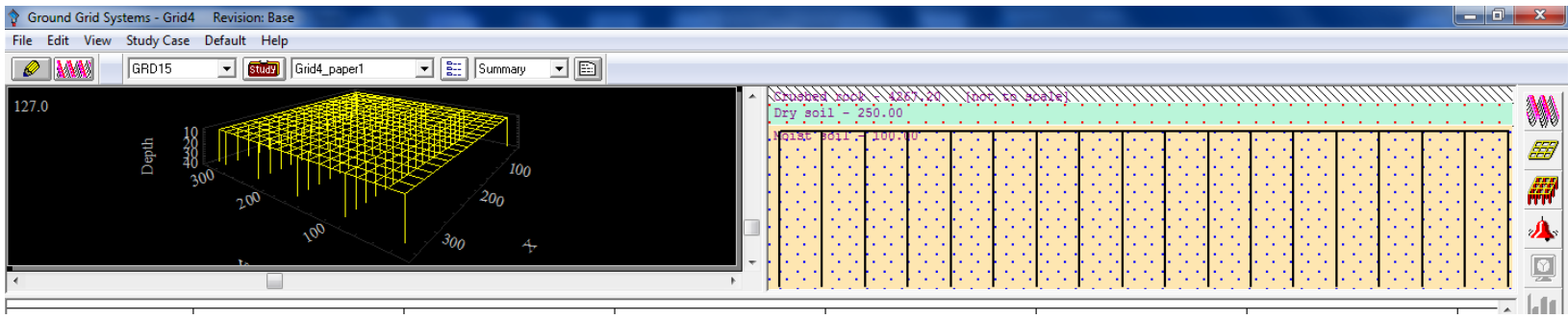

Fig; 3 Ground Grid Systems with different simulation.

Table 2: Input parameters

\begin{tabular}{|l|c|c|}
\hline \multicolumn{2}{|c|}{ Parameters } & FEM \\
\hline Conductors Depth (ft) & 8.00 \\
\hline \multirow{2}{*}{ Grid Length (ft) } & Lx & 300 \\
\cline { 2 - 3 } & Ly & 300 \\
\hline \multirow{2}{*}{ No of Conductors } & X & 15 \\
\cline { 2 - 3 } & Y & 15 \\
\hline \multirow{2}{*}{ S Separation Length } & X & 21.4 \\
\cline { 2 - 3 } & Y & 21.4 \\
\hline Total no of Conductors & 30 \\
\hline No of rods & 34 \\
\hline Length in (ft ) & 100 \\
\hline Rod Diameter & 4 inch \\
\hline Ground Resistance & $0.37 \Omega$ \\
\hline Total Cost of Design & $\$ 1868$ \\
\hline
\end{tabular}

Figures 9, 10 and 11 shows different Touch, Step, Absolute potential after the simulation of design using FEM method.

Cases 1 and 2 are analyzed below. The analysis is performed to evaluate the most effective and economical ground grid mesh structure using IEEE method and FEM method. See appendix A and B for details of simulation results. The results of Case 1 and Case 2 have been presented and based upon these results, the two are compared in order to determine the most effective and cost effective method for ground grid mesh design. 


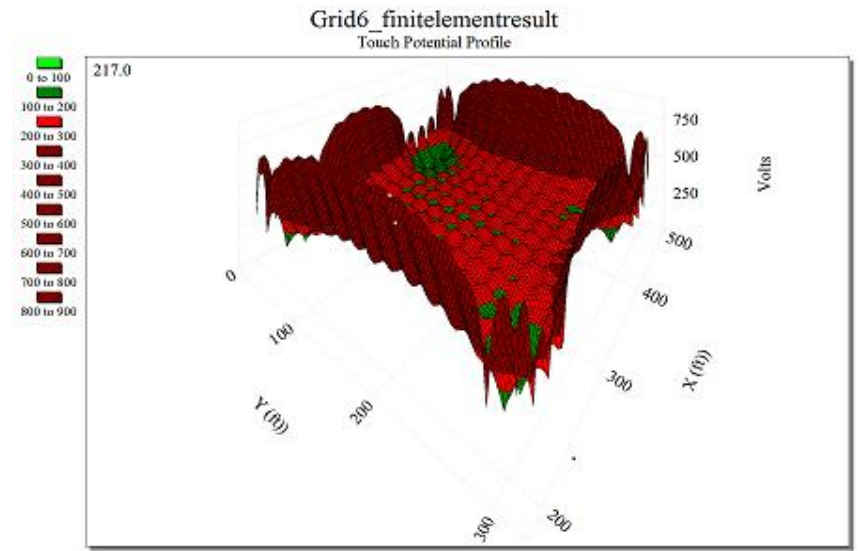

Fig.9. Touch Potential Grid6_finitelementresult Absolute Potential Profile

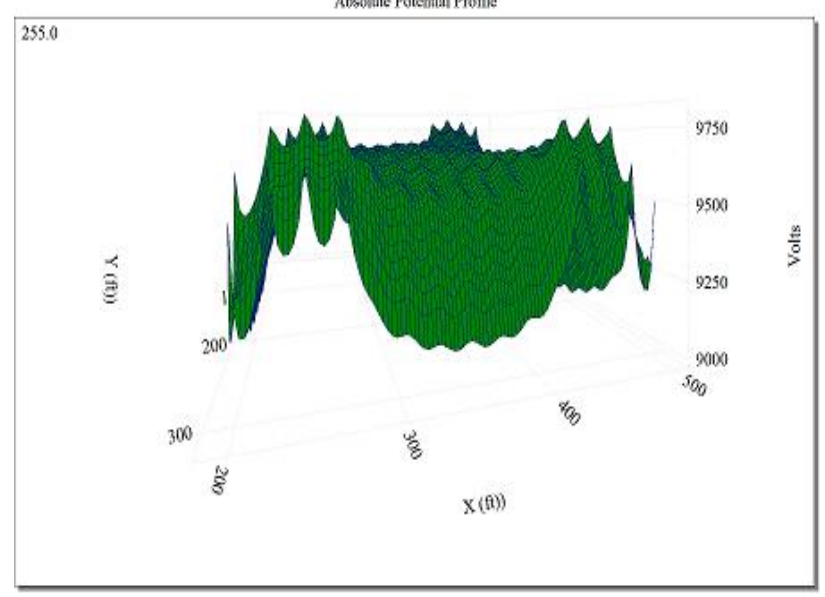

Fig 11 Absolute potential profile

Because of the lower cost of design, the grid configuration for optimized number of rods and conductors for Case 1 are used

Required conductors: The analysis of the results shows that ground grid mesh structure is more when using FEM method (9000ft) than IEEE method (3600ft).

Rod required: The number of rod is more for IEEE method than FEM. But the per length of each rod for FEM (100ft) is more than IEEE (32.80ft) thereby making the rods for FEM more effective than IEEE, since FEM reaches to the lower earth layers which are less affected by environmental factors such as temperature and moisture content.

Design cost: The results shows that the cost of ground grid mesh design is more using FEM method (\$1868) than IEEE method (\$966). The reason is that the horizontally and vertically laid conductors are more in mesh designed by FEM than IEEE methods.

Effectiveness: The final result shows that the ground resistance $\left(\mathrm{R}_{\mathrm{g}}\right)$ of ground grid mesh structure design using FEM is lower $(0.374 \Omega)$ than IEEE method $(0.480 \Omega)$. This means that the rate of dissipation of

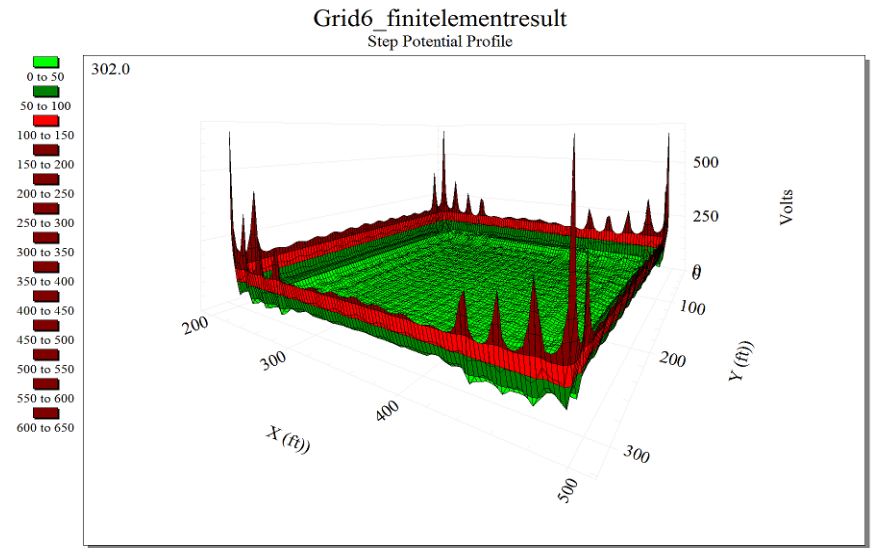

Fig. 10 Step potential voltage profile.

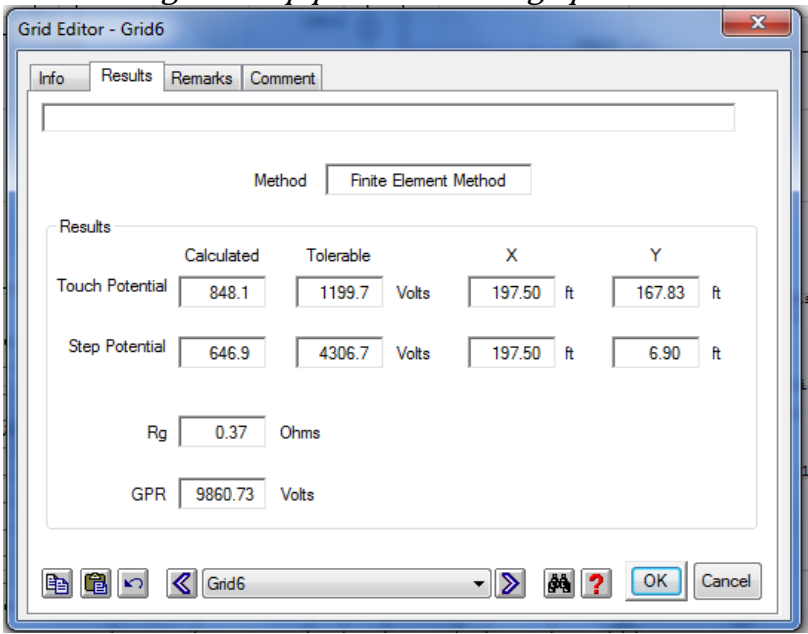

Fig. 12: Final result of FEM analysis

short circuit current will be higher for grid mesh designed by FEM than one done with IEEE method.

It was discovered that the best grid configuration is for the Case 1 which optimized the number of rods and conductors used. Finally this work has shown that design done with FEM is better that of IEEE methods in terms of effectiveness but is cost more than IEEE method.

\section{CONCLUSIONS}

The result in this paper shows the ground grid mesh design of a $132 / 33 \mathrm{kV}$ substation with expected maximum grid current of 26kA. Two different methods FEM and IEEE, based on Etap 12 software were used for the design analysis to determine tolerable limit of different design parameters (GPR, mesh voltage, step and touch voltages and $R_{g}$ ). The design by FEM method after satisfying the safety criteria limits showcased a highly effective mesh grid structure that can withstand more excessive fault current when compared to IEEE method ie ( $\mathrm{R}_{\mathrm{g}}$ FEM $\left.<\mathrm{R}_{\mathrm{g} \text { IEEE}}\right)$ and an expensive mesh structure when compared to IEEE method as shown in case 1. 
Grid mesh structure degenerate with time, this leads to various design parameters GPR, Estep Etouch and $\mathrm{R}_{\mathrm{g}}$ exceeding their safety criteria limits overtime therefore it is importance that a method that accommodate the smallest property be used. FEM method is suggested since it gives more realistic results when implemented than the conventional method.

\section{REFERENCE}

[1] R.M KhiderSulima "Earthing Design using Finite Element Method".

[2] Dwarka Prasad and H.C. Sharma, "Design of Grounding System for High Voltage Substations". International Journal of Engineering and Advanced Technology (IJEAT), Volume 2, Issue 6, pp. 61-65, August (2013).

[3] Research Project of PEA's Ground Grid in Substation and Grounding in HC and LV Distribution System, Thailand, (2006).

[4] M.G Unde, and B. Kushare, "Grounding Grid Performance of Substation in Two Layer Soil- a Parametric Analysis" International journal of Engineering Sciences \& Emerging Technologies (IJEST) Volume 1,Issue 2, pp.69-76, Feb. (2012).

[5] AhdabElmorshedy, RabahAmer, SherifGhoneim, and Holger Hirsch," Surface Potential and Energy Conference, Pp. 501-505, Nov. (2006).

[6] John Finn, IEEE Substation Earthing-Shedding light on the Black Art, IEE Seminar, Savoy Place London, May (2000).

[7] Swapmil, G. Shah and Nitin, R. Bhasme, "Design of Earthing System for HV/EHV AC Substation. International Journal of Engineering and Advanced Technology Volume 6, Issue 6, 2597-2605, Jan. (2014).
[8] IEEE Guide for Safety in ac substation Grounding, ANSI/IEEE Std. 80. IEEE Society, New York. (2000).

[9] IEEE Guide for Measuring Earth Resistivity, Ground Impedance and Earth Surface Potentials of a Grounding System IEEE std 81 $1^{\mathrm{Tm}}$-(2012/2013).

[10] Muhammad, U.C, MBilal .C., Adnan B., M.usman Aslam. "A Comparison of Ground Grid Mesh Design and Optimization for $500 \mathrm{kv}$ Substation using IEEE 80-2000 and Finite Element Methods". Electrical and Electronics Engineering: $A n$ International Journal (ELELIJ), Volume 4, No 1, pp. 131-145, Feb. (2015).

[11] DwarkaPrasaad, and H.C. Sharma, "Significance of step and touch voltages", IJSCE Volume -1, Issue -5, November (2011).

[12] "IEEE Guide for Safety in AC Substation Grounding", IEEE std. 80, USA, (2000).

[13] S. Raju, and G. Pardharadhi, "Optimal Design Planning of Ground Grid for Outdoor Substations in MEA's Power Distribution Substation", Journal of Engineering Research and Applications June (2012).

[14] J.G. Sverak, "Simplified analysis of Electrical Gradients above a Ground Grid; part 1 - How good is the present IEEE method?'. IEEE Transactions on Power Apparatus and Systems, Volume PAS-103, pp. 7-25, Jan (1984).

[15] J. A. Guemes, F. E. Hernando, F. Rodrigez, J. M. Ruiz "A Practical Approach of Determining the Grounding Grids", IEEE Transactions on Power Delivery, Vol. 21 No.3, July (2006)

[16] S.J. Schwarz, "Analytical Expressions for the Resistance of grounding Systems", AIEE Transactions, Vol.73 part III-B pp. 1011-1016, (1954).

\section{APPENDIX A}

\begin{tabular}{lll} 
Project: & ETAP & Page: 1 \\
Location: & $12.6 .0 \mathrm{H}$ & Date: $11-21-2015$ \\
Contract: & & SN: \\
Engineer: & Study Case: GRD15 & Filename:umuahia network \\
& & Revision: Base \\
\hline
\end{tabular}

\section{Ground Grid Input Data}

System Data:

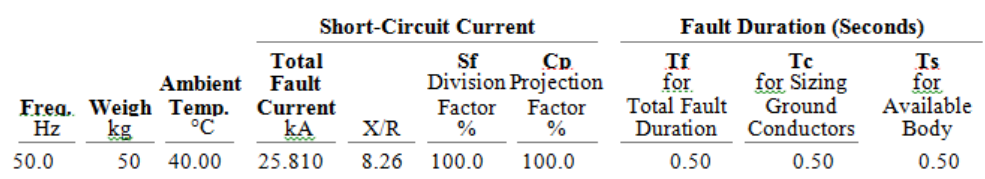


Soil Data:

\begin{tabular}{|c|c|c|c|c|c|c|c|}
\hline \multicolumn{3}{|c|}{ Surface Material } & \multicolumn{3}{|c|}{ Upper Layer Soil } & \multicolumn{2}{|c|}{ Lower Layer Soil } \\
\hline Material Type & $\begin{array}{c}\text { Resistivity } \\
\text { Ohm.m }\end{array}$ & $\begin{array}{c}\text { Depth } \\
\mathrm{ft}\end{array}$ & Material Type & $\begin{array}{c}\text { Resistivity } \\
\mathrm{Ohm.m}\end{array}$ & Depth & MaterialType & $\begin{array}{c}\text { Resistivity } \\
\text { Ohm.m }\end{array}$ \\
\hline Crushed rock & 4267.2 & 9.999 & Dry soil & 250.0 & 5.00 & Moist soil & 100.0 \\
\hline
\end{tabular}

\begin{tabular}{|c|c|c|c|c|c|c|c|}
\hline Material Constant & & Conductivity & $\begin{array}{c}\alpha_{\mathrm{r} F \text { Factor }} \\
@ 20^{\circ} \mathrm{C}\end{array}$ & K0@ & $\begin{array}{c}\text { Fusing } \\
\text { Temperatu }\end{array}$ & $\begin{array}{l}\text { Resistivity of } \\
\text { Ground } \\
\text { (a) } 20^{\circ} \mathrm{C}\end{array}$ & $\begin{array}{l}\text { Thermal } \\
\text { Capacity } \\
\text { Per Unit }\end{array}$ \\
\hline Conductor/Rod & Type & $\%$ & $1 /{ }^{\circ} \mathrm{C}$ & $0^{\circ} \mathrm{C}$ & ${ }^{\circ} \mathrm{C}$ & micro ohm.cm & $\mathrm{J} /\left(\mathrm{cm}^{3} \cdot{ }^{\circ} \mathrm{C}\right)$ \\
\hline Conductor \& Rod & Copper-clad steel rod & 20.0 & 0.00378 & 245.0 & 1084.0 & 8.62 & 3.85 \\
\hline
\end{tabular}

Rod Data:

\begin{tabular}{|c|c|c|c|c|}
\hline $\begin{array}{c}\text { Diameter } \\
\text { inch }\end{array}$ & $\begin{array}{c}\text { Length } \\
\mathrm{ft}\end{array}$ & $\begin{array}{l}\text { No. of } \\
\text { Rods }\end{array}$ & Arrangement & $\begin{array}{l}\text { Cost } \\
\text { \$/Rod }\end{array}$ \\
\hline 0.750 & 32.80 & 75 & Rods Throughout Grid & 2.00 \\
\hline
\end{tabular}

Grid Configuration:

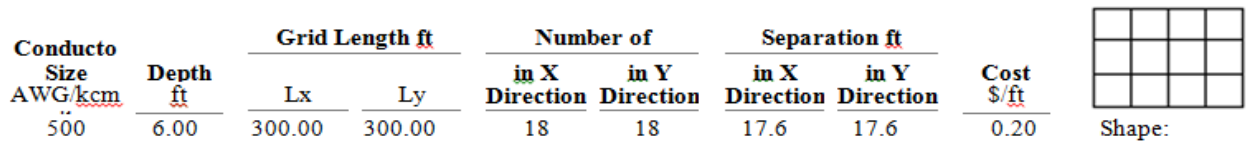

Cost:

\begin{tabular}{|c|c|c|c|c|c|c|}
\hline \multicolumn{3}{|c|}{ Conductor } & \multicolumn{3}{|c|}{ Rod } & \multirow[b]{2}{*}{$\underset{S}{\text { Total Cost }}$} \\
\hline $\begin{array}{l}\text { Total } \\
\text { No. }\end{array}$ & Total Length & $\underset{\$}{\text { Cost }}$ & $\begin{array}{c}\text { Total } \\
\text { No. }\end{array}$ & $\begin{array}{l}\text { Total Length } \\
\mathrm{ft}\end{array}$ & $\underset{S}{\text { Cost }}$ & \\
\hline 36 & 10800.00 & 2160.00 & 75 & 2460.00 & 150.00 & 2310.00 \\
\hline
\end{tabular}

Project:

Location:

Contract:

Engineer:
ETAP

$12.6 .0 \mathrm{H}$

Study Case: GRD15
Page: 1

Date: 12-08-2015

SN:

Filename:umuahia network Revision: Base

\section{Ground Grid Summary Report}

\begin{tabular}{|c|c|c|c|c|c|c|c|c|c|c|c|}
\hline \multirow{3}{*}{$\begin{array}{c}\text { Rg } \\
\text { Ground } \\
\text { Resistance } \\
\text { ohm }\end{array}$} & \multirow{3}{*}{$\begin{array}{c}\text { GPR } \\
\text { Ground } \\
\text { Potential Rise } \\
\text { Volts }\end{array}$} & \multicolumn{5}{|c|}{ Maximum Touch Potential } & \multicolumn{5}{|c|}{ Maximum Step Potential } \\
\hline & & \multirow{2}{*}{$\begin{array}{c}\text { Tolerable } \\
\text { Volts }\end{array}$} & \multirow{2}{*}{$\begin{array}{c}\text { Calculate } \\
\text { Volts }\end{array}$} & \multirow{2}{*}{$\begin{array}{c}\text { Calculated } \\
\%\end{array}$} & \multicolumn{2}{|c|}{ Coordinates (ft) } & \multirow{2}{*}{$\begin{array}{c}\text { Tolerable } \\
\text { Volts }\end{array}$} & \multirow{2}{*}{$\begin{array}{c}\text { Calculate } \\
\text { Volts }\end{array}$} & \multirow{2}{*}{$\begin{array}{c}\text { Calculated } \\
\%\end{array}$} & \multicolumn{2}{|c|}{ Coordinates $(\mathrm{ft})$} \\
\hline & & & & & $\mathrm{X}$ & $\mathrm{Y}$ & & & & $\mathrm{X}$ & $\mathrm{Y}$ \\
\hline 0.374 & 9860.7 & 1199.7 & 848.1 & 70.7 & 197.5 & 167.8 & 4306.7 & 646.9 & 15.0 & 197.50 & 6.90 \\
\hline \multicolumn{2}{|c|}{ Total Fault Current } & \multicolumn{2}{|c|}{$25.810 \mathrm{kA}$} & \multicolumn{3}{|c|}{ Reflection Factor $(\mathrm{K})$ : } & & -0.889 & & & \\
\hline \multirow{2}{*}{\multicolumn{2}{|c|}{ Maximum Grid Current: }} & \multirow{2}{*}{\multicolumn{2}{|c|}{$26.369 \mathrm{kA}$}} & \multicolumn{4}{|c|}{ Surface Layer Derating Factor (Cs): } & 0.986 & & & \\
\hline & & & & \multicolumn{4}{|c|}{ Decrement Factor (Df): } & 1.022 & & & \\
\hline
\end{tabular}

